\title{
Entre objetos no seleccionados y argumentos degradados*
}

\section{Between unselected objects and demoted arguments}

\author{
María Mare \\ Universidad Nacional del Comahue \\ Consejo Nacional de Investigaciones Científicas y Técnicas (CONICET)
}

\begin{abstract}
RESUMEN. El objetivo de este artículo es abordar la manera en la que se manifiestan los argumentos de los verbos latinos prefijados por ante, circum, trans y praeter desde un enfoque neo-construccionista. La propuesta discute de qué manera los argumentos que parecen vincularse semánticamente con el prefijo obtienen la información morfológica de caso y qué sucede cuando alguno de ellos es degradado. Este recorrido permite plantear que las oraciones pasivas constituyen evidencia empírica en contra de que el caso del objeto no seleccionado por el verbo base sea asignado por el prefijo preposicional, ya que en estas construcciones este objeto presenta caso nominativo, en lugar de acusativo, algo inesperado si se postula que está subordinado a la preposición.
\end{abstract}

Palabras clave: estructura argumental, latín, Morfología Distribuida, caso.

Abstract. The aim of this paper is to study argument alternations in Latin verbs prefixed by ante, circum, praeter and trans from a neo-constructivist approach. The proposal endeavors to explain

Data de recepción: 19-03-2019 " Data de aceptación: 14-07-2019.

* Mi especial agradecimiento a los coordinadores y a los participantes de la sesión monográfica «Teorías lingüísticas contemporáneas y lenguas clásicas», en el marco del XLVIII Simposio de la Sociedad Española de Lingüistica (2019). También agradezco los valiosos comentarios de los evaluadores anónimos. 
the manner in which different arguments obtain their case features and what happens when one of them is demoted. Along these pages we argue that passive sentences provide empirical evidence against the hypothesis that non-selected objects acquire their case features from the prepositional prefix. The main reason for rejecting this is that in these constructions the non-selected object presents nominative case, instead of accusative case. This result is unexpected if this object is subordinated to the preposition.

Keywords: argument structure, Latin, Distributed Morphology, case.

\section{INTRODUCCIÓN}

La introducción de un nuevo argumento como resultado de la prefijación de un predicado de base verbal es un fenómeno frecuente en latín, como ha sido señalado por diferentes estudiosos (Kühner y Stegmann 1997 [1914]; Ernout y Thomas 1953; Oniga 2005; Pinkster 2015; García Hernández 1996, entre otros). En estos trabajos, se menciona particularmente el caso de prefijos que se corresponden con preposiciones cuyos complementos nominales son acusativos, como circum, trans, praeter. Los ejemplos de (1) y (2) muestran este fenómeno cuando se prefijan los verbos intransitivos volare 'volar' y fluere 'fluir', respectivamente. Subrayamos el prefijo y el argumento agregado, que manifiesta caso acusativo.

(1) a. coturnices (...) austro non volant (Plin. Nat. 10.35)

'las codornices (...) no vuelan con el viento del Sur'

b. perdices non transvolant Boeotiae fines (Plin. Nat. 10.41)

'las perdices no vuelan más allá de la frontera de Beocia'

(2) a. Crysas est amnis qui per Assorinorum agros fluit (Cic. Verr. 2.4.96)

'Crisas es el río que corre a través de los campos de los asorios'

b. nunc eam (Antiochiam) circumfluunt Meander et Orsinus (Plin. Nat. 5.108) 'ahora el Meandro y el Orsino la rodean'

c. flumen Turiam, quod Valentiam parvo intervallo praeterfluit (Sall. Hist. 2.54)

'el río Turia que corre cerca de Valencia por un corto intervalo'

A partir de este fenómeno se han realizado diferentes observaciones que se recuperan a lo largo de este trabajo. En primer lugar, se ha considerado relevante identificar si el verbo prefijado es de movimiento o si se trata de un predicado estativo (Kühner y Stegmann 1997[1914]: 265). En segundo lugar, se ha señalado que este fenómeno puede darse también con verbos base transitivos, obteniendo como resultado una 
construcción de doble acusativo (Kühner y Stegmann 1997 [1914]: 305; Ernout y Thomas 1953: §49; Oniga 2005: 243; Pinkster 2015: 171). Finalmente, se ha destacado que el argumento agregado no puede funcionar como sujeto en la construcción pasiva correspondiente por su dependencia con el prefijo y, por lo tanto, conserva el caso acusativo (Kühner y Stegmann 1997[1914]:305; García Hernández 1996: 28; Pinkster 2015: 172).

El objetivo de este trabajo es revisar estas afirmaciones a la luz de los datos y de las consideraciones que nos permiten realizar los modelos de estructura argumental que se plantean actualmente en el marco de la Gramática Generativa. En este sentido, exploramos las posibles respuestas a dos interrogantes: (A) ¿por qué las construcciones de doble acusativo son marginales con verbos cuyas formas pasivas presentan un argumento en acusativo (Moussy 2005)?; (B) ¿cuál es la relación entre los argumentos agregados y los argumentos degradados (pasivización)? A partir de estas preguntas, proponemos un análisis que, a nuestro entender, permite dar cuenta de la diferencia indicada en (A), ya que se enmarca en un enfoque que no considera las construcciones pasivas como el resultado de una «transformación» de la oración activa, sino como una estructura diferente en la que están involucradas las mismas raíces. Asimismo nuestro análisis propone que los límites para el cambio de función de los argumentos agregados (de objeto a sujeto) no se derivan de su dependencia del prefijo, sino de cuestiones estructurales relacionadas con la jerarquía de los argumentos en la configuración sintáctica (B).

La discusión se organiza de la siguiente manera. En la sección 2, se presentan los aspectos metodológicos de esta investigación y la descripción general de los ítems involucrados en el fenómeno en cuestión. En $\S 3$ nos detenemos en las construcciones de objetos no seleccionados. Utilizamos esta denominación de manera equivalente a argumentos agregados, siguiendo la literatura sobre el tema (Acedo-Matellán y Mateu 2013, Acedo-Matellán 2016). Tanto el término 'no seleccionado' como el término 'agregado' hacen referencia a la modificación de la estructura argumental del verbo base, es decir, son 'no seleccionados' o 'agregados' con respecto a las propiedades del verbo base. La sección 4 está dedicada a lo que denominamos degradación de argumentos (demotion) y se centra en la pasivización de los verbos prefijados, a fin de determinar qué argumentos pueden funcionar como sujetos en la estructura pasiva. Finalmente, sistematizamos los principales aportes descriptivos y teóricos que supone el recorrido propuesto en estas páginas. 


\section{ASPECTOS METODOLÓGICOS Y DESCRIPTIVOS}

\subsection{Consideraciones sobre el corpus}

El corpus que constituye la base empírica de esta investigación está compuesto por obras en prosa de autores clásicos ${ }^{1}$, fundamentalmente de César (100-44aC); Cicerón (106-43aC); Livio (59 aC- 17dC); Plinio (23-79dC); Salustio (86-34aC); Varrón (116-27aC); Vitruvio (80/70 aC-15aC). Esta selección se realizó siguiendo las consideraciones de Ernout y Thomas (1953: §28) y Bortolussi (2005), por un lado, y McLachlan (2012), por el otro. Los dos primeros autores destacan el empleo regular de objetos agregados en acusativo en autores del período republicano, mientras que McLachlan fundamenta la necesidad de constituir corpora relativamente homogéneos, tanto temporal como espacialmente. Los datos que conforman nuestro corpus fueron recopilados a partir de las bases Perseus Project y Loeb Classical Library. Asimismo, se utilizaron los diccionarios Oxford Latin Dictionary (2012) y el Nuevo diccionario latino-español etimológico de De Miguel y De Morante (1903) para definiciones y búsqueda de ejemplos.

Con respecto a los verbos analizados, como mencionamos en la introducción, se consideraron los prefijados por ante 'delante', circum 'alrededor', praeter 'por delante' y trans 'a través, al otro lado', procurando, en la medida de lo posible, seleccionar aquellos en los que la misma base verbal se combinara con más de uno de los prefijos estudiados. Como veremos en detalle en $\$ 2.2$, la elección de los elementos prefijales estuvo motivada por el hecho de que los cuatro tienen un correlato con preposiciones que asignan caso acusativo a sus complementos ${ }^{2}$. Siguiendo las observaciones que recuperamos en la introducción, se distinguieron verbos base transitivos (Tabla 1) y verbos base intransitivos (Tabla 2). En la próxima sección, comentaremos algunos aspectos referidos a la distinción que hacen Kühner y Stegmann entre predicados de movimiento (Bewegung) y estativos (Raume).

Seguimos la definición de Crocco Gàleas y Iacobini (1993) que incluye autores del siglo I aC al siglo II dC, dada la relativa homogeneidad de la norma escrita. Dicha homogeneidad, en nuestro caso, se sostiene más aún por la selección de textos en prosa, en su mayoría técnicos.

2 Revuelta Puigdollers (2019) señala que el caso de trans es llamativo ya que su uso como preposición es significativamente inferior a su ocurrencia y distribución como prefijo. 


\begin{tabular}{|l|l|l|l|l|}
\hline Verbo base & ante & circum & praeter & trans \\
\hline Claudo 'cerrar' & $\begin{array}{l}\text { circumcludo } \\
\text { 'cerrar rodeando' }\end{array}$ & & $\begin{array}{l}\text { tra(ns)duco } \\
\text { circumduco 'llevar/ } \\
\text { conducir alrededor' } \\
\text { lugar a otro' }\end{array}$ \\
\hline Fero 'llevar' & $\begin{array}{l}\text { antefero 'llevar } \\
\text { delante, anteponer' }\end{array}$ & $\begin{array}{l}\text { circumfero 'llevar/ } \\
\text { hacer circular } \\
\text { alrededor' }\end{array}$ & $\begin{array}{l}\text { circumiacio } \\
\text { 'ubicar, arrojar } \\
\text { alrededor' }\end{array}$ & un lugar a otro' \\
\hline $\begin{array}{l}\text { Iacio 'ubicar, } \\
\text { arrojar' }\end{array}$ & $\begin{array}{l}\text { circummitto 'enviar } \\
\text { alrededor' }\end{array}$ & $\begin{array}{l}\text { praetermitto 'dejar } \\
\text { pasar' }\end{array}$ & $\begin{array}{l}\text { tra(ns)icio 'arrojar } \\
\text { a través' } \\
\text { de un lugar a otro' }\end{array}$ \\
\hline Mitto 'enviar' & & & \\
\hline
\end{tabular}

TABLA 1. Verbos base transitivos

\begin{tabular}{|c|c|c|c|c|}
\hline Verbo base & ante & circum & praeter & trans \\
\hline Eo 'ir' & $\begin{array}{l}\text { anteeo 'ir delante, } \\
\text { anteceder' }\end{array}$ & $\begin{array}{l}\text { circumeo 'ir } \\
\text { alrededor' }\end{array}$ & $\begin{array}{l}\text { praetereo 'pasar } \\
\text { adelante/de largo' }\end{array}$ & $\begin{array}{l}\text { transeo 'pasar de } \\
\text { un lugar a otro' }\end{array}$ \\
\hline Fluo 'fluir' & & $\begin{array}{l}\text { circumfluo 'fluir } \\
\text { alrededor' }\end{array}$ & $\begin{array}{l}\text { praeterfluo 'fluir/ } \\
\text { correr delante' }\end{array}$ & $\begin{array}{l}\text { transfluo 'pasar } \\
\text { flotando de un lugar } \\
\text { a otro/por encima' }\end{array}$ \\
\hline Sisto 'pararse, estar' & & $\begin{array}{l}\text { circumsisto } \\
\text { 'pararse alrededor' }\end{array}$ & & \\
\hline Venio 'venir' & $\begin{array}{l}\text { antevenio 'venir } \\
\text { antes, adelantarse' }\end{array}$ & $\begin{array}{l}\text { circumvenio } \\
\text { 'situarse alrededor, } \\
\text { rodear' }\end{array}$ & & \\
\hline Volo 'volar' & & $\begin{array}{l}\text { circumvolo 'volar } \\
\text { alrededor' }\end{array}$ & $\begin{array}{l}\text { praetervolo 'pasar } \\
\text { volando' }\end{array}$ & $\begin{array}{l}\text { transvolo 'volar } \\
\text { más allá' }\end{array}$ \\
\hline
\end{tabular}

TABLA 2. Verbo base intransitivos

\subsection{Prefijos, preposiciones, adverbios}

Los cuatro ítems que aparecen como prefijos se reconocen en otros contextos morfosintácticos a partir de los cuales pueden clasificarse como preposiciones o como adverbios, de ahí, la denominación de prefijos preposicionales que suele encontrarse en la literatura (por ejemplo, Oniga 2005). Desde la propuesta teórica en la que se enmarca esta investigación, i.e., un enfoque neo-construccionista, la discusión sobre clases de palabras se circunscribe a la presencia de raíces ensambladas en diferentes contextos morfosintácticos. En este sentido, un ítem como circum no pertenece a 
una clase particular, sino que la pertenencia que manifieste es derivada. Por lo tanto, si la raíz $\sqrt{ }$ CIRCUM se inserta en una estructura transitiva como la de (3), estará funcionando como una preposición, mientras que si se ensambla en una estructura intransitiva como la de (4), se dirá que es un adverbio (Mare 2018). Asumiendo esto, se vuelve central definir cómo es la estructura en la que esta raíz termina siendo clasificada como un prefijo.

(3) Estructura transitiva

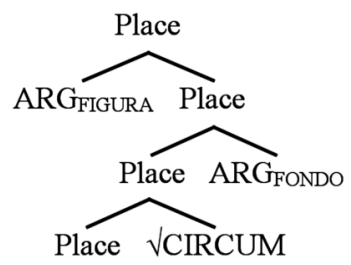

(4) Estructura intransitiva

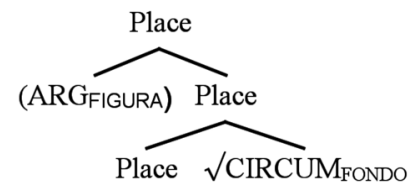

Como puede observarse, los esquemas de arriba siguen la terminología cognitiva de Talmy (2000), en la que hay una predicación definida por la proyección Place que establece una relación entre dos entidades: una se presenta como estática o en movimiento (Figura) con respecto a la otra entidad (Fondo). Seguimos así la propuesta desarrollada por Acedo-Matellán y Mateu 2013 y Acedo-Matellán 2016.

Como muestran los ejemplos a continuación, los cuatro ítems pueden aparecer como preposiciones y como adverbios en combinación con verbos de movimiento/cambio de posición y predicados estativos (a excepción de praeter), comportamiento que Kühner y Stegmann (1997[1914]:265) reconocen para los prefijos correspondientes.

Ante

Adverbio: delante; hacia adelante

(5) praelabitur ante (Cic. Arat. 246(12))

'se desliza hacia adelante'

Preposición: en frente a

(6) a. In fossam quae erat ante oppidum (Caes. Gal. 2.31.4) [predicado estativo] 'En un foso que estaba delante de la ciudad'

b. ante currum tuum duceres (Cic. Verr. 2.5.67) [verbo de movimiento] 'lleves ante tu cuádriga'

\section{Circum}

Adverbio: alrededor 
(7) ne stantes circum suis umbris obscurent lucem (Vitr. 5.10.4)

'que las sombras de los que están alrededor no cubrieran la luz'

Preposición: alrededor de

(8) a. quae circum Aquileiam hiemabant (Caes. Gal. 1.10.3) [predicado estativo] 'que pasaban el invierno alrededor de Aquilea'

b. ducebat eos circum civitates (Cic. Ver. 2.3.65) [verbo de movimiento]

'los condujo por diferentes ciudades'

\section{Praeter}

Preposición: por delante de, a lo largo de (across)

(9) a. Eurotas, is qui praeter Lacedaemonem fluit (Cic. Inv. 2.96) [verbo de movimiento] 'el río Eurotas, que fluye al lado del Lacedemon'

b. praeter castra Caesaris suas copias traduxit (Caes. Gal. 1.48.2)

'condujo a sus tropas por delante del campamento de César'

\section{Trans}

Adverbio: del otro lado

(10) eius (signi) contraria (pars) (...) trans locis patentibus ex obscuri egreditur ad lucem (Vitr. 9.1.4)

'la parte contraria del astro, (...) al otro lado, en regiones abiertas, emerge desde la oscuridad a la luz'.

Preposición: más allá de, a través de

(11) a. Ut se trans Alpis sequerentur (Cic. Fam. 11.13.3) [verbo de movimiento]

'Para que lo siguieran al otro lado de los Alpes'

b. Galli... trans pontem Anienis castra habuere (Liv. 7.9.6) [predicado estativo]

'los galos ubicaron su campamento del otro lado del puente del Aniene'

c. qui trans Rhenum incolunt (Caes. Gall. 1.1.4) [predicado estativo]

'que habitan al otro lado del Rin'

Cabe destacar que además de la relación locativa que establecen estos ítems, puede reconocerse una predicación vinculada con la manera. La interpretación de manera se observa fundamentalmente en circum y praeter. Para el rol como preposiciones, Baños Baños (2009: 315) propone los matices de significado que se presentan en la Tabla 3. A los cuatro ítems que constituyen el foco de este estudio, agregamos otras construcciones preposicionales que, como veremos, aparecen con frecuencia junto a los verbos prefijados que analizamos (in/ad/per + acusativo). 


\begin{tabular}{|l|c|c|c|c|}
\hline Preposición & Ubicación & Dirección & Vía & Modo \\
\hline ANTE & + & + & & \\
\hline CIRCUM & + & +3 & & + \\
\hline PRAETER & $(+)$ & $(+)$ & + & \\
\hline TRANS & + & + & & \\
\hline AD + acusativo & + & + & & + \\
\hline IN + acusativo & $(+)$ & + & & + \\
\hline PER + acusativo & + & & + & + \\
\hline
\end{tabular}

TABLA 3. Matices de significado de las preposiciones según Baños Baños (2009)

Este autor destaca que con respecto a la ubicación ante supone un referente espacial único de posición anterior y circum señala una posición exterior alrededor de una superficie que se puede recorrer. En el caso de trans, plantea que cuando el referente espacial se concibe como una superficie que se puede recorrer, agrega al significado de per + acusativo la idea de que se franquea el límite doble (principio y final) y ejemplifica este hecho con el ejemplo de (12) (Baños Baños 2009: 320).

(12) trans Nessum amnem incolunt (Liv. 45.30.3)

'viven al otro lado del río Neso'

Con respecto a praeter, Baños Baños indica que supone un trayecto, el lugar por donde se pasa (vía). Para ejemplificar este valor ofrece el ejemplo que presentamos en (13).

(13) dua ad Luceriam ferebant viae, altera praeter oram superi maris..., altera per Furculas Caudinas (Liv. 9.2.6)

'dos caminos conducían a Lucesia: uno, bordeando más allá de la costa del mar Superior..., el otro a través de las Horcas Caudinas»

El resto de los sintagmas preposicionales que expresan dirección coincide básicamente con las marcas de ubicación y aporta, por tanto, especificaciones similares a las mencionadas. El esquema de (14) ilustra estos valores, con respecto a la entidad representada por el rectángulo gris. Los puntos negros indican ubicación, las curvas al interior del rectángulo representan uno de los valores de circum (ver Revuelta Puigdollers 2016) y el círculo punteado representa el significado de circum como rodear, ya sea por medio del movimiento, ya de manera estática.

En Mare (2018) discutimos la interpretación de dirección como una característica inherente de circum. 


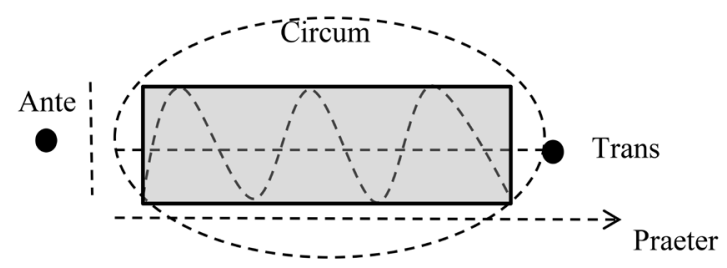

\section{OBJETOS NO SELECCIONADOS}

Los cuatro ítems prefijales se corresponden tanto con preposiciones, i.e., con configuraciones transitivas en las que el argumento interno manifiesta caso acusativo (3), como con adverbios, i.e., con estructuras que no presentan un complemento (4). Dado que los verbos prefijados por estos elementos pueden transitivizarse, se han buscado explicaciones en términos de incorporación (Baker 1988): un sintagma preposicional (SP) se ensambla a la estructura verbal con su complemento y luego el núcleo P se incorpora al núcleo $\mathrm{V}$ por medio del movimiento nuclear. Como consecuencia, queda un argumento marcado con caso acusativo que se interpreta como argumento de todo el núcleo complejo.

Este tipo de abordaje presenta dos problemas. En primer lugar, es necesario discutir el lugar en el que se ensambla el SP, ya que con verbos como claudere 'cerrar' cualquier SP locativo que se agregue se ensamblaría en una posición de adjunto y no de complemento, con lo que el movimiento nuclear debería definirse en otros términos. El segundo problema que vemos para un análisis incorporacionista es que asume algún tipo de proyeccionismo, ya que lo que termina siendo un prefijo participaría siempre en una estructura preposicional en la que proyectaría todos sus argumentos. Empíricamente, es difícil de sostener esta idea ya que, como vimos, estos mismos ítems funcionan como adverbios con valor locativo o con valor de manera. Además, los complementos preposicionales en latín no pueden ser nulos u omitirse aunque el referente sea recuperable del contexto discursivo y esto sí es posible con los objetos no seleccionados, dado que funcionan como cualquier argumento verbal.

En esta sección presentamos los ejemplos de objetos no seleccionados y definimos los patrones argumentales que se reconocen (\$3.1). En $\S 3.2$, exponemos brevemente el modelo de estructura argumental que seguimos y en $\S 3.3$ desarrollamos las estructuras propuestas para nuestros datos. 


\subsection{Verbos base intransitivos y transitivos}

El primer aspecto que llama notablemente la atención al distinguir la transitividad de los verbos base es la productividad de objetos no seleccionados cuando el verbo base es intransitivo, contra la escasa presencia de construcciones de doble objeto cuando el verbo base es transitivo. A continuación ofrecemos los ejemplos correspondientes a cada grupo. Con subrayado destacamos el argumento con caso acusativo y colocamos entre corchetes otros constituyentes a los que nos referiremos más adelante.

\subsubsection{Verbos base intransitivos}

Eo

(15) a. (Philippus) qui [aetate et consilio $]_{\mathrm{ABL}}$ ceteros anteibat (Sall. Hist. 1.75) ${ }^{4}$ '(Filipo) quien superaba a los demás en edad y juicio'

b. partem (equitum) circumire exteriores munitiones... iubet (Caes. Gal. 7.83.2) 'y que otra parte (de la caballería) rodeara las fortificaciones exteriores... ordenó'

c. Praeteriit villam meam Curio (Cic. Att. 10.4.8)

'Curion pasó de largo por mi casa de campo'

d. Taurum ipse transisti? (Cic. Fam. 3.8.6)

'¿...que tu mismo cruzaste el Tauro?'

Fluo

(16) a. ut tanta circumfluxerit nos cervorum aprorum et ceterarum quadripedum multitudo (Varr. Rus. 3.13.3)

'que nos rodea una gran multitud de ciervos, cabras y otros animales cuadrúpedos'

b. amnemque praeterfluentem moenia (Liv. 41.11.3)

'había un río que corría más allá de la ciudad'

c. si vas fiat e ligno eius, vina transfluere ac remanere aquam (Plin. Nat. 16.78)

'si se hace un vaso con la madera de zarza, el vino pasa a través de este y permanece el agua'

Sisto

(17) a. Illi circumsistunt hominem (Caes.Gal. 5.7.9)

'Estos rodearon al hombre'

b. quem perterriti omnes Arverni circumsistunt (Caes. Gal. 7.8.4)

'y todos los arvernos lo rodean espantados'

$4 \quad$ En Cicerón el argumento agregado se encuentra en caso dativo.

(i) ii, qui [anteire ceteris ${ }_{\mathrm{DAT}}$ virtute $_{\mathrm{ABL}}$ ] putantur (Cic. Off. 2.37)

'quienes son considerados superiores a otros en habilidad' 
c. centuriones armati Mettium circumsistunt (Liv. 1.28.7)

'los centuriones armados rodean a Metio'

\section{Venio}

(18) a. Ac [per tramites occultos] exercitum Metelli antevenit (Sall. Jug. 48.2)

'Y por senderos ocultos (Jugurta) se anticipó al ejército de Metelo'

b. quem per arbitrum circumvenire non posses (Cic. Rosc. 9.25)

'(el hombre) al que no puedes vencer ante un árbitro'

Volo

(19) a. circumvolare sedem illam (Quint. Inst. 2.6.7)

'volar alrededor del nido'

b. sententiaeque saepe acutae non acutorum hominum sensus praetervolant (Cic. Or. 3.223)

'y las sentencias, por demasiado agudas, a veces se dejan entender sólo de ingenios delicados'

c. ut plerumque vela navium transvolent. (Plin. Nat. 9.8)

'que (los delfines) a menudo pasan volando sobre las velas de los barcos'

\subsubsection{Verbos base transitivos}

(20) si nubes solem circumcludent (Plin. Nat. 18.119)

'si las nubes forman un anillo alrededor del sol'

(21) a. ut [per colles] (...) circumducat equites (Liv. 28.33) $)^{5}$

'(le ordenó a Laelio) que condujera la caballería (...) por las colinas'

b. Germani, quos propterea Caesar traduxerat [Rhenum] (Caes. Gall. 8.13.2)

'los germanos a quienes César ya había conducido del otro lado del Rin'

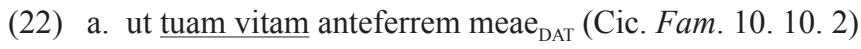

'para hacerme preferir tu vida a la mía'

b. ad gemitus volnerum (...) circumferebant ora oculosque. (Liv. 22.5.4)

'volvían sus caras y sus ojos hacia los gemidos de los heridos (...)'

(i) Quos Pompeius (...) [omnia sua praesidia] circumduxit

'Pompeius (...) carried them [horses and servants] over all the camp' (Pinkster 2015: 173)

Sin embargo, no hay acuerdo entre las distintas versiones con respecto a este segundo acusativo. De Valbuena (1798) y el volumen correspondiente de la Bibliotheca Classica Latina (1820), entre otros, reconocen la preposición per antes de omnia sua praesidia. Este SP de trayecto aparece de manera recurrente tanto con circumduco como con duco (y con transduco). 
c. concilium [Lutetiam Parisiorum] transfert (Caes. Gall. 6.3.4) ${ }^{6}$

'trasladó el consejo a Lutecia'

(23) a. agitare dux coepit, si quo modo posset vallum circumicere (Liv. 25.36.5)

'el general comenzó a considerar si de algún modo podía formar una defensa alrededor'

b. Cum [Rhodanum] copias omnis traiecissem (Cic. Fam. 10.11.2)

'Una vez que hube cruzado el Rodano con todas mis tropas...'

(24) a. Perseum filium cum modica manu circummisit (Liv. 40.22.13)

'Y envió a su hijo Perseo a acercarse con una pequeña fuerza' (a la ciudad de Petra)

b. Praetermitto ruinas fortunarum tuarum (Cic. Cat. 1.6.14)

'También paso por alto la ruina de tu fortuna'

c. grues cum loca calidiora petentes maria transmittant (Cic. Deo. 2.125)

'las grullas, cuando cruzan los mares en busca de lugares cálidos'

\subsubsection{Recapitulación}

Los patrones argumentales que aparecen de manera general en la voz activa se resumen a continuación:

a. Presencia de un objeto no seleccionado por el verbo base.

i. Transitivización de un verbo intransitivo (un argumento con caso acusativo).

ii. Bitransitivización de un verbo transitivo (dos argumentos en caso acusativo).

b. Ningún argumento añadido al verbo base, con lo que se obtiene la interpretación de manera.

La construcción de doble acusativo es productiva con trans-, fundamentalmente con transduco. Sin embargo, llama la atención la restricción léxica (cursos de agua y cadenas montañosas) que presenta el segundo acusativo, en relación a las alternativas que se encuentran para el objeto no seleccionado de los verbos base intransitivos. Dicha restricción léxica se observa también en los verbos base intransitivos, en los que el SD con caso acusativo es productivo cuando el referente es un río o una cadena montañosa. De lo contrario, aparece de manera recurrente el SP in + acusativo.

Bortolussi lo considera un acusativo lativo. Ver más adelante. 
Bortolussi (2005) plantea que los riesgos de ambigüedad entre los diversos complementos en caso acusativo se explican por tres tipos de restricciones:

a) la rareza del doble acusativo propiamente dicho y, en contraste, la relativa frecuencia de construcciones pasivas, que eliminan una de las formas de acusativo.

b) las restricciones léxicas que pesan sobre los complementos de los preverbos: su referencia es exclusivamente un lugar; para trans- se dice que la gran mayoría de los usos se refieren a cursos de agua, que si no son suficientemente conocidos, aparecen acompañados por flumen, para evitar la confusión con un acusativo lativo que designa a una villa.

(25) [Volturnum flumen] traducere audebat exercitum (Liv. 23.36.10)

'Osó hacer cruzar el río Volturno a su ejército' (Lit. Osó conducir a su ejército al otro lado del río Volturno)

c) la pertenencia a un registro técnico: la mayoría de los ejemplos pertenecen a la lengua técnica: agricultura (circumdo), religión (circumago,-fero), milicia (circumduco, traduco, transporto).

El doble acusativo como resultado de la prefijación de trans- se observa fundamentalmente con verbos de movimiento que suponen un cambio de posición.

Transduco

(26) a. tres iam partes copiarum Helvetios [id flumen] traduxisse (Caes. Gal. 1.12.2) 'que los helvecios ya habían conducido a tres partes de sus tropas del otro lado de este río (Ródano)'

b. Germani, quos propterea Caesar traduxerat [Rhenum] (Caes. Gal. 8.13.2)

'los germanos a quienes César ya había conducido del otro lado del Rin'

Transicio

(27) a. Itaque pridie Nonas Iunias omnis copias [Isaram] traieci (Cic. Fam. 11.13.3)

'Y así, el 4 de junio, crucé el Isara con todas mis tropas' (y destruye el puente que había construido)

b. $\underline{\text { se }}[\underline{\text { Alpis }}]$ Antonius traiecerit (Cic. Fam. 11.9.2)

si Antonio se traslada a sí mismo al otro lado de los Alpes

En este sentido, resulta relevante observar qué otros SSPP aparecen con los verbos prefijados. Uno de los más frecuentes con verbos base transitivos es la construcción de per + acusativo, fundamentalmente en verbos como $d u c o$, que también se combinan con este SP (28c). 
(28) a. [per castra] qua vellent circumduci iussit (Liv. 30.29.2)

'Thereupon ordenó que fueran conducidos por el campamento, por donde quisieran ir'

b. quod [per fines Sequanorum] Helvetios traduxisset (Caes. Gal. 1.19.1)

'el hecho de que había conducido a los helvecios a través de los territorios de los secuanos'

c. nam quibus commeatibus invito illo [per illius provinciam] legiones ducerem? (Cic. Fam. 10.31.4)

¿por qué caminos conduje mis legiones a través de su provincia contra su voluntad?

Pinkster (2015: 10.22-10-24) los considera adjuntos de trayecto y destaca que las frases preposicionales con per aparecen como alternativa de construcciones nominales desnudas marcadas con caso con acciones de movimiento o que implican movimiento desde Livio en adelante. Señala también una diferencia semántica entre per + acusativo y ablativo solo: el constituyente encabezado por per implica atravesar un obstáculo potencial, mientras que el ablativo solo no supone un obstáculo. ${ }^{7}$

Por su parte, Revuelta Puigdollers (2016) señala para los casos de prefijación con circum- que el punto de referencia (Landmark) puede manifestarse como un nombre con caso acusativo o en la construcción de per + acusativo, preferida fundamentalmente en verbos base transitivos (circumago, circumduco). La presencia de per + acusativo bloquea la interpretación 'circular' y se mantiene la interpretación que indica movimiento de un punto a otro.

Otro de los SSPP que se encuentran de manera recurrente es in + acusativo. Álvarez Huerta (2009: 147) señala que el acusativo lativo alterna con in + acusativo. «Cuando se expresa el término de un movimiento mediante la preposición in no se marca simplemente una idea de proximidad (esto lo expresa $a d+$ acusativo), sino que se indica que el movimiento llega al interior de un lugar (Ernout-Thomas 1953: 33).» Se esperaría, por lo tanto, encontrar secuencias de verbo base intransitivo con un SD acusativo como argumento agregado y un SP de in + acusativo indicando dirección y meta. Sin embargo, la alternancia que se encuentra de manera productiva en relación a los verbos prefijados en trans- (transeo, traicio, transduco, transmitto) es acusativo cuando se hace referencia a un curso de agua o a una cadena montañosa (Alpes, Apeninos) e in + acusativo en otros $\operatorname{casos}^{8}$.

$7 \quad$ Pinkster agrega que, en poesía, la elección entre las dos alternativas está determinada también por razones métricas.

8 Lo que mostramos en la Tabla 4 es una tendencia. Como nos señala un evaluador anónimo, hay ejemplos en los que aparece un acusativo que no refiere ni a ríos ni a cadenas montañosas.

(i) Sed multi mortales (...) vitam sicuti peregrinantes transiere 'muchos mortales han pasado a través de la vida como peregrinos' (Sall. Cat. 2.8).

(ii) Domiti filius transiit Formias 'el hijo de Domicio atravesó Formias' (Cic. Att. 9.3.1). 


\begin{tabular}{|l|l|}
\hline Acusativo solo & In + acusativo \\
\hline Caes. Gal. & Caes. Gal. \\
1.12.1 Id (flumen Arar) ... transibant & 1.28 .3 in Helvetiorum fines transirent \\
1.13.2 flumen transirent & 8.53 .1 in alia omnia transiit \\
$\begin{array}{l}\text { 1.31.11 Rhenum transirent } \\
\text { 1.33.3 Rhenum transire }\end{array}$ & \\
4.1.1 flumen Rhenum transierunt & \\
\hline Cic. Att. & Cic. Att. \\
5.18.1 Euphraten transierunt & 5.18 .1 in meam provinciam transierint \\
& 10.13 .1 in Aenariam transire \\
\hline Cic. Fam. & Cic. Fam. \\
3.8.4 Taurumve transirent & 1.9 .24 in Ciliciam non transieris \\
3.8.5 Taurum ipse transisti? & 15.4 .7 in Ciliciam transisset \\
11.10.4 Appenninum transisset & \\
15.1.1 transisse Euphratem & \\
\hline Liv. & Liv. \\
21.25.1 Hiberum transisse & 41.5 .5 transire in Galliam \\
21.25.2 Alpes iam transisset & 41.7 .7 in Histriam transisset? \\
21.38.5 Rhodanum transierit & 41.8 .11 in civitatem Romanam (...) transibant \\
& 42.65 .1 in Phalannaeum agrum transeunt \\
& 44.16 .1 in Macedoniam transisset \\
\hline
\end{tabular}

TABLA 4. Acusativo solo e in + acusativo con transeo

En suma, el objeto agregado con caso acusativo que aparece de manera productiva con los verbos prefijados por trans- no se comportaría como un argumento interno prototípico, como sí parecen hacerlo los objetos agregados en los demás casos. Si bien es necesaria mayor investigación con respecto a este punto (ver Revuelta Puigdollers 2019), las alternancias que hemos mostrado en este apartado nos permiten proponer lugares de ensamble diferentes en la estructura, que procuraremos justificar en los próximos apartados.

\subsection{Presentación del modelo teórico}

Nuestro análisis se inscribe dentro de la Morfología Distribuida (Halle y Marantz 1993, 1994), i.e., asumimos la inserción tardía de los exponentes fonológicos, el agregado post-sintáctico de material disociado y el principio de la Sintaxis por todos

En efecto, Moussy (2005) reconoce un comportamiento diferenciado entre estos acusativos y otros argumentos internos, ya que refieren a lo que él denomina un Lieu (lugar) y no un Theme (tema). A esto agrega que en el caso de transeo, el Lugar puede devenir en sujeto de la construcción pasiva, función que con otros predicados (otros verbos prefijados o los verbos con doble acusativo) le corresponde al Tema. 
lados (Syntax all-the-way-down), en el sentido de que el componente sintáctico es el único responsable de las combinaciones de unidades de significado. La estructura de la gramática que postula este modelo es la de (29).

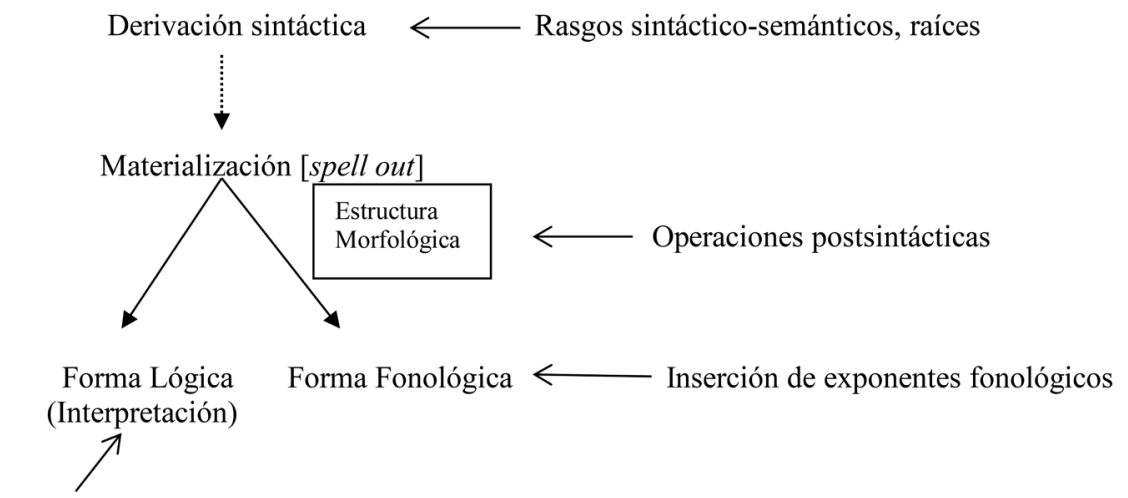

Acceso a la Enciclopedia

Las operaciones que tienen lugar en la Sintaxis son ensamble externo (Merge) y ensamble interno (movement) y están involucradas tanto en la formación de palabras y como en la de oraciones. Algunas líneas de investigación dentro de la MD proponen que las operaciones que dan lugar a la materialización de la concordancia (Bobaljik 2008) y del caso (McFadden 2004) ocurren únicamente en el componente denominado Estructura Morfológica (EM). Las operaciones que se producen en la EM no afectan al componente Conceptual-Intencional (Forma Lógica), sino que dan cuenta de la falta de isomorfismo entre lo que genera la Sintaxis y lo que finalmente se materializa.

Ahora bien, con respecto a la estructura argumental, seguimos fundamentalmente la propuesta de Acedo-Matellán y Mateu (2013) y Acedo-Matellán (2016). En este sentido, reconocemos que la combinación de Raíces sin categorizar con elementos relacionales (Mateu 2002), tales como Path y Place (Svenonius 2008), dan lugar a las diferencias de significado y de selección argumental'.

Utilizamos Path y Place a los fines expositivos y no como denominaciones referidas únicamente a relaciones locativas. Estas proyecciones refieren al hecho de que haya un único elemento relacional en tanto predicación que supone un estado (Place) o dos elementos relacionales que implican una transición: Path se ensambla por encima de Place e implica un cambio de estado/locación en el que el Fondo representa ese estado/locación final. 
(30)

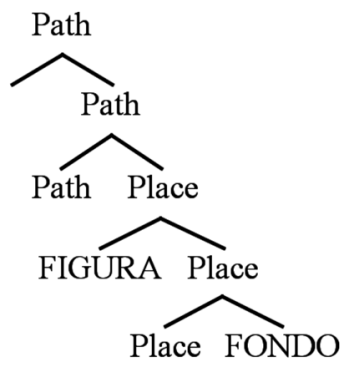

En la configuración de (30) las raíces pueden ensamblarse en dos posiciones: como complemento de Place, es decir, en la posición de Fondo, o como adjunto de Place, estableciendo el tipo de relación que se da entre el argumento Figura y el argumento Fondo. Recuérdense los esquemas (3) y (4) en §2.2. Por encima de Path, se ensamblan los núcleos funcionales que definen categorías, i.e., si se trata de una construcción verbal o nominal. Para el conjunto de datos que abordamos, el categorizador relevante es $v$ (erbalizador), que no proyecta estructura. Finalmente, los agentes y las causas son introducidos por la proyección denominada Voice (SVoice en términos de Kratzer 1996), cuya presencia desencadena la interpretación de una entidad que origina el evento descripto por las relaciones de Path y Place. Las opciones con respecto a la interpretación de los argumentos que presenta Acedo-Matellán (2016: 44) son las siguientes:

Originador: argumento en el Especificador de Voice

Figura: argumento en el Especificador de Place

Fondo central: argumento o raíz en el complemento de Place cuando no se proyecta Path.

Fondo terminal: argumento o raíz en el complemento de Place cuando se proyecta Path.

Medidor (Measurer): argumento que se mueve de Espec-Place a Espec-Path.

Co-evento (manera): adjunto del categorizador $v$.

Conformación (tipo de relación espacial): adjunto de Place

Como se sigue de esta breve presentación del modelo, los lugares de ensamble tanto de las raíces como de los argumentos determinan la manera en la que se interpretarán en la Forma Lógica. Esta idea será retomada en las próximas secciones. 


\subsection{Estructuras propuestas}

De los verbos analizados, los que presentan un argumento agregado de manera más productiva son los prefijados en circum- y trans-, tal como ha sido señalado en la literatura. Sin embargo, y en línea con Bortolussi (2005), el objeto agregado en los verbos prefijados por trans- presenta algunas diferencias con los argumentos internos prototípicos, ya que manifiesta restricciones léxicas, alterna con otros SSPP (fundamentalmente, con in + acusativo) y puede mantener el caso acusativo en las oraciones pasivas, como veremos en $\S 4$. En el caso de los prefijados en circum-, en cambio, el objeto agregado se comporta como un argumento interno prototípico.

En un enfoque neo-construccionista como el que presentamos en $\S 3.2$, el agregado de un argumento tiene lugar en las capas más bajas, antes del ensamble de los categorizadores (ver Acedo Matellán 2016), en este caso, del categorizador verbal (v). El argumento 'aparece' por una combinación de proyecciones en la estructura, en la que lo que denominamos prefijo se ensambla como una raíz no individuada (ni fonológica, ni semánticamente) que se interpreta en el componente Conceptual-Intensional de acuerdo a la estructura en la que aparece (Acquaviva 2008).

Así, el agregado de argumentos en los ejemplos analizados tiene lugar en configuraciones en las que se proyectan elementos relacionales no presentes en el verbo base. En este sentido, un verbo como venire 'venir' que supone desplazamiento, pero no codifica un cambio de locación de una entidad con respecto a otra, adquiere este sentido cuando es prefijado por ante, como en el ejemplo de (18a) que recuperamos a continuación.

(31) Jugurtha (...) exercitum Metelli antevenit (18a)

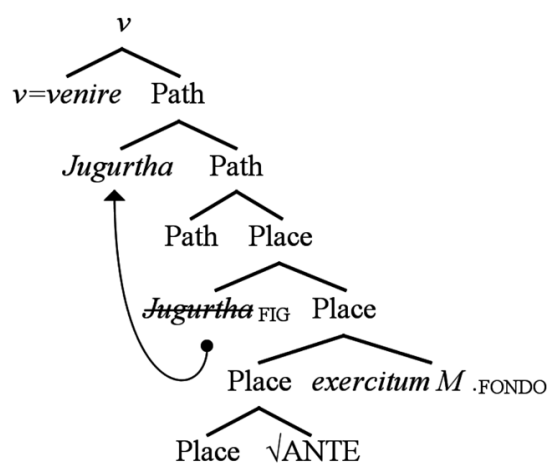


Esta relación entre entidades se deriva de la presencia de Place y la interpretación de un cambio de locación es el resultado de que por encima de Place se ensamble Path. El argumento desplazado es Jugurtha y se interpreta como Medidor porque se mueve desde Espec-Place a Espec-Path. Finalmente, el tipo de relación entre los elementos se sigue del ensamble de $\sqrt{ }$ ANTE como adjunto de Place (Conformación). Este mismo tipo de configuración seguimos para otros verbos base intransitivos prefijados, como circumfluere y praetervolant, con la diferencia de que en estos casos no tendríamos únicamente el categorizador $v$, sino que hallamos un co-evento (fluere y volare, respectivamente), es decir, una raíz ensamblada a $v$.

(32) eam circumfluunt Meander et Orsinus (2b)

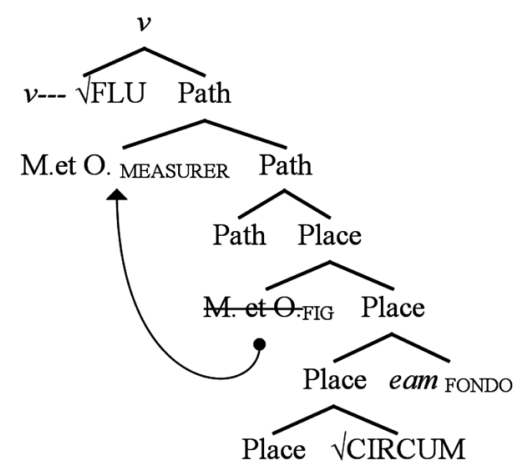

(33) sententiae acutae non acutorum hominum sensus praetervolant (19b)

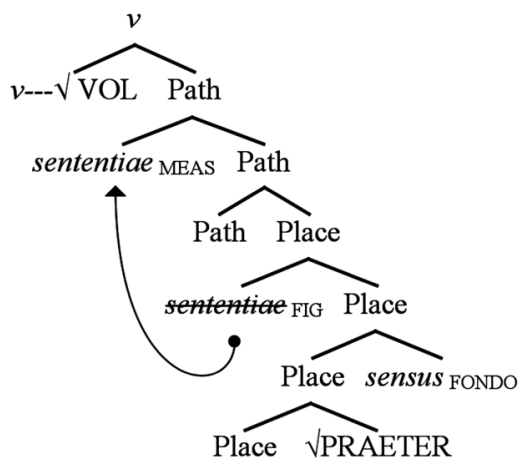


En cuanto a los verbos prefijados por trans- parece haber en nuestro corpus acotado, al menos dos tipos. Un tipo que presentaría una estructura similar a las de (31) a (33), en la que el argumento que aparece con caso acusativo está en la posición de Fondo, es decir, se comporta como un argumento interno prototípico y no alterna, en principio, con otros SSPP. Aquí se encontrarían verbos como transfluere (16c) o transvolare (19c). Otros verbos, en cambio, presentarían un objeto con caso acusativo con características más adverbiales, que alternan con otros constituyentes locativos y que presentan fuertes restricciones léxicas. Como se muestra en (34) la raíz $\sqrt{T R A N S}$ es el elemento que se ensambla como complemento de Place y se interpreta, por lo tanto como Fondo. Aquí ubicaríamos a transeo ( $\$ 3.1 .3$ y nota al pie 8 ) y como veremos, también a las construcciones de doble acusativo. En estos casos, ese objeto con caso acusativo se ensambla como adjunto de la proyección Path, ya que semánticamente refiere al trayecto, y constituye un SP con un núcleo nulo ${ }^{10}$. Es decir, el caso acusativo no estaría dado por la estructura como se define para las configuraciones de arriba (por Generalización de Burzio de manera general), sino por su relación de localidad con un núcleo $\mathrm{P}$, de manera similar al complemento de in en la construcción de in + acusativo.

(34) Taurum ipse transisti

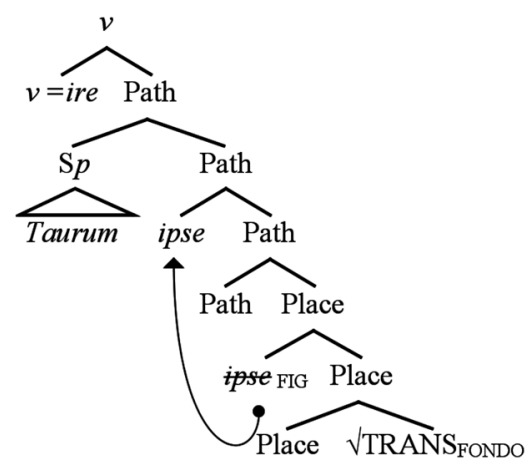

En cuanto a las construcciones de doble acusativo, tendríamos también dos tipos. Por un lado, aquellas en las que el segundo nombre con caso acusativo es un objeto agregado en la posición de Fondo, como se presenta de manera abstracta en la estructura de (35) y que sería muy poco frecuente o inexistente, como vemos en los ejemplos de verbos base transitivos prefijados por ante, circum y praeter.

10 Sin dudas la presencia de este «adjunto» está motivada por la combinación de raíces y argumentos en la configuración. 
(35) Con un objeto agregado

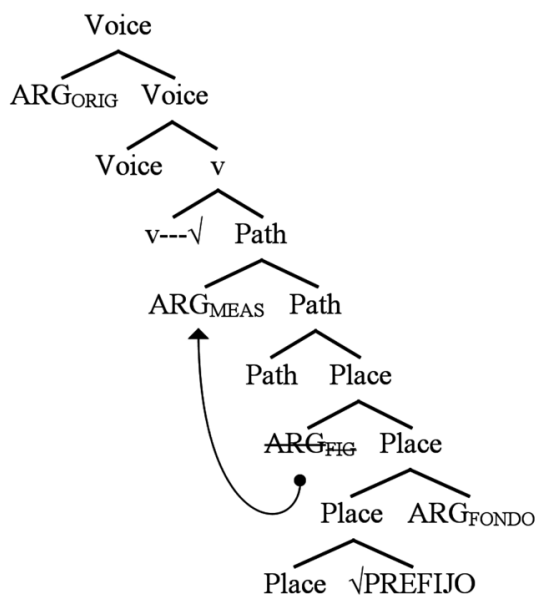

El segundo tipo se corresponde con la configuración en la que el nombre en acusativo es parte de un $\mathrm{S} p$ adjunto de Path. Este patrón es el que manifiestan los verbos base transitivos prefijados por trans- que conforman nuestro corpus.

(36) Rhodanum copias omnis traiecissem

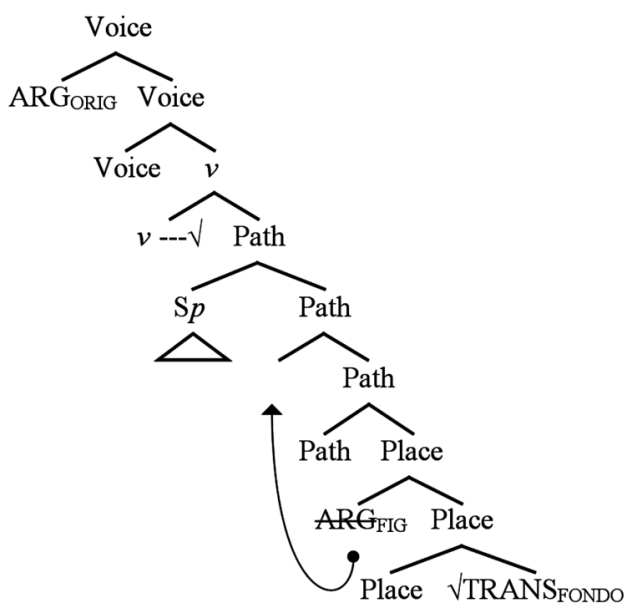


Una vez establecidas estas configuraciones, en el próximo apartado nos detendremos en la degradación de argumentos y los aspectos relativos a la morfología de caso. El eje de la discusión es la falta de correlación entre el número de pasivas con argumentos en caso acusativo y el número de construcciones activas de doble objeto, aspecto destacado también por Moussy (2005).

\section{ARGUMENTOS DEGRADADOS}

Como mencionamos en la introducción, otro aspecto que caracterizaría a las construcciones que nos competen es el hecho de que existe una dependencia sintáctica entre el objeto agregado y el prefijo. La consecuencia de esto es que ese objeto no puede funcionar como sujeto en la construcción pasiva. En general, esta observación se presenta al referir a las construcciones de doble acusativo y, como vimos, se plantea que esta es la razón por la que el objeto agregado sigue apareciendo con caso acusativo. En esta sección revisamos los problemas de formulaciones como estas y discutimos la degradación de argumentos a partir de las configuraciones propuestas en §3. Además, nos interesa volver sobre un punto esencial para las descripciones de los datos, a saber, la relación entre las oraciones activas y pasivas.

\subsection{Construcciones pasivas con verbos base intransitivos y transitivos}

A continuación recuperamos ejemplos de construcciones pasivas, siguiendo la división en cuanto a la transitividad del verbo base que propusimos para las formas activas. En negrita marcamos el constituyente que funciona como sujeto y en subrayado el argumento agregado. La coincidencia de ambas marcas indica que el argumento agregado cumple la función sintáctica de sujeto en la oración pasiva. Utilizamos cursivas para los argumentos degradados.

\subsubsection{Construcciones pasivas con verbos base intransitivos}

(37) quo a proximis quisque minime anteiri volt (Liv. 6.34.7)

'que no se desea ser superado en lo más mínimo por los amigos más cercanos'

(38) a. quod flumen uno omnino loco pedibus (...) transiri potest (Caes. Gal. 5.18.1)

'río que podía ser cruzado a pie por un solo lugar (...)' (Tames)

b. quod non fere ante autumnum Elaver vado transiri solet (Caes. Gal. 7.35.1) ${ }^{11}$ 'ya que el Allier no podía vadearse antes del otoño'

11 Secundum flumen Elaver ducit (Caes. Gal.7.34.2) ‘a lo largo del río Allier' (secundum + acusativo). 
(39) a. magister equitum (...) ex insidiis circumvenitur (Liv.10.3.6)

'el jefe de caballería fue rodeado por una emboscada'

b. ipse (...) ne ab omnibus civitatibus circumsisteretur (Caes. Gal. 7.43.5)

'que no fuera rodeado por todas las ciudades'

(40) a. quae praeteriri nullo modo poterant (Cic. S. Rosc. 42)

'esas cosas que de ningún modo podrían pasarse por alto'

b. ut nulla fere pars orationis silentio praeteriretur (Cic. Brut.22)

'que casi ninguna parte de su oración se dejaba pasar en silencio'

En resumen, las construcciones pasivas a partir de verbos base intransitivos, en las que el ítem léxico que aparece como objeto agregado en la forma activa es el que cumple la función sintáctica de sujeto en la pasiva (38) y (39), muestran que la dependencia del objeto agregado con respecto al prefijo tiene un carácter semántico y no estructural. De lo contrario, se esperaría que el argumento agregado manifestara en todas las construcciones caso acusativo, por tratarse del caso que asignan las preposiciones correspondientes (ante, circum, praeter y trans).

\subsubsection{Construcciones pasivas con verbos base transitivos}

(41) a. (Pompeius) ne duobus circumcluderetur exercitibus (Caes. Civ. 3.30.7) '(Pompeyo se aleja del lugar) para no quedar encerrado por dos ejércitos'

(42) a. Atque omnes illo ad munitionem copiae traducuntur (Caes. Gal. 7.45.6) 'y todas sus tropas son enviadas allí para protección' ('was brought across to that spot' Trad. Loeb)

b. ne maior multitudo Germanorum [Rhenum] traducatur (Caes. Gal. 1.31.16) 'para que una gran multitud de germanos no fuera conducida al otro lado del Rin'

(43) quod fasces anteferrentur (Caes. Civ. 3.106.4)

'puesto que las fasces eran llevadas adelante'

(44) a. cum eae (tabulae) ut mos est circumferrentur (Cic. Att. 1.16.4)

'cuando estas (las cuentas de Metelo Numídico), fueron presentadas como es costumbre'

b. multi ad mili remedia [rubetam noctu [arvo] circumferri] iubent (Plin. Nat. 18.64) 'para la enfermedad del mijo, muchos recomiendan que un sapo sea llevado alrededor del campo la noche anterior'

(45) a. Nam [in eum ${ }_{\mathrm{i}}$ ] culpa et summum odium transferetur [qui id negavit $]_{\mathrm{i}}$ (Cic. Inv. 2.22) 'entonces toda la culpa y el mayor odio serán transferidos a aquel que lo negó' 
b. si aut causa aut factum [in alium] transferetur (Cic. Inv. 1. 15)

'si tanto la causa como el acto mismo son atribuidos a otros'

c. ita imperium semper ad optumum quemque a minus bono transferetur (Sall. Cat. 2.6) 'y así la autoridad será siempre transferida desde el menos bueno al mejor'

(46) quod anguis domi [vectem] circumiectus fuisset (Cic. Div. 2.61) ${ }^{12}$

'el hecho de que en su casa una serpiente se había enrollado alrededor de un cerrojo'

(47) a. neque ullum interim telum per pactiones loquentium traiciebatur (Caes. Civ. 3.19.1) 'sin que en el ínterin se arrojara ningún proyectil por mutuo acuerdo'

b. dum istinc copiae traiciantur (Cic. Fam. 10.11.2) 'en tanto esas tropas sean trasladadas desde allí (Roma)'

(48) Legationes [in omnes partes] circummittuntur (Caes. Gal. 7.63.1)

'Las embajadas son enviadas hacia todas las direcciones'

(49) a. ne quod genus a me ipso laudis meae praetermittatur (Cic. Att. 1.19.10) 'para que por mi parte no quede sin cultivar ningún género en mi propio elogio'

b. A me nullum tempus praetermittitur de tuis rebus et agendi et cogitandi (Cic. Fam. 1.5.4) $)^{13}$

'no dejo pasar ninguna ocasión de actuar y planear por tus intereses'

(50) exercitus equitatusque equitibus Romanis administrantibus (...) celeriter transmittitur (Caes. Gal. 7.61.2)

'pasó prontamente del otro lado al ejército y la caballería (...) bajo la supervisión de los caballeros romanos'

En las construcciones pasivas con verbos base transitivos encontramos las mismas alternativas en las que se manifiestan distintos objetos para las formas activas (ablativo solo, in + acusativo, acusativo solo). Además en muchos casos aparece únicamente el argumento interno funcionando como sujeto, con la presencia o no del argumento degradado. En todos los casos, el argumento que establece la concordancia con el verbo es aquel que se espera que aparezca más alto en la estructura.

12 Continúa: Tum esset, inquit, ostentum, si anguem vectis circumplicavisset 'sería un ostento, le dijo, si el cerrojo se hubiera enroscado en la serpiente'.

13 Ego tamen nullum diem praetermitto. (Cic. Att. 9.14.2) 'No dejo pasar ningún día'. 


\section{2 ¿Cómo se degrada un argumento?}

Las construcciones con argumentos degradados y morfología pasiva se encuentran tanto en verbos base intransitivos como verbos base transitivos. Para estos últimos, dicha combinación junto con la presencia de un nombre con caso acusativo ha dado lugar a las observaciones mencionadas en $\S 1$. Ahora bien, hay dos maneras generales de entender la degradación de argumentos: (A) asumir que el argumento estaba presente en la estructura y que se borró o degradó como consecuencia de la aplicación de alguna operación, vinculada estrictamente con el movimiento (Chomsky 1957 y una versión minimalista en Collins 2005); (B) asumir que la construcción es defectiva en algún sentido y, por lo tanto, no puede tener lugar el ensamble de un argumento, de la manera esperada (Embick 2004, entre otros). En relación a nuestros datos, notamos que las construcciones de doble acusativo se ejemplifican en diccionarios y gramáticas por medio de oraciones pasivas que presentan un argumento con caso acusativo. Este tipo de descripción y presentación de los datos refleja la concepción teórica descripta en (A). Sin embargo, mientras que las construcciones pasivas resultan sumamente productivas en el período estudiado, las construcciones de doble acusativo son infrecuentes o presentan las tendencias discutidas en $§ 3.1 .3$. En este sentido, un modelo que no suponga que las construcciones pasivas son el resultado de movimientos (o transformaciones), permite explicar esta diferencia. Además, permite entender la presencia de un nombre con caso acusativo sin recurrir a la idea de que ese caso está regido por el prefijo, algo difícil de sostener tanto empírica (por las alternancias encontradas) como teóricamente (por los movimientos que permite la sintaxis y las relaciones de mando-c).

La pregunta central es si un objeto no seleccionado puede «convertirse» en sujeto de una pasiva.

En el ejemplo de (46) pareciera que no: anguis, la Figura, es el sujeto y vectem 'cerrojo' aparece en caso acusativo y se interpreta como el Fondo. Sin embargo, el hecho de que vectem no sea el sujeto en la oración pasiva, no se derivaría de su condición como argumento agregado por circum- (circum vectem), sino por el hecho de que hay un elemento nominal más local para establecer las relaciones de concordancia con T, i.e. anguis. Esto se ve de manera clara en los contrastes de (51) y (52).

(51) a. Tua te altera patria (...) Messana circumvenit (Cic. Ver. 2.4.17)

'Hasta tu segunda patria (...), Mesana te ataca'

b. magister equitum (...) ex insidiis circumvenitur (Liv.10.3.6)

'el jefe de caballería (...) fue rodeado por una emboscada' 
(52) a. Illi circumsistunt hominem (Caes. Gal. 5.7.9)

'Estos rodearon al hombre'

b. ipse (...) ne ab omnibus civitatibus circumsisteretur (Caes. Gal. 7.43.5)

'él mismo (...) para que no fuera rodeado por todas las ciudades'

Siguiendo a Embick (2000, 2004), entonces, asumimos que las construcciones pasivas tienen un $v$ agentivo (Voice) defectivo, es decir, que no admite el ensamble del argumento externo en la posición de especificador. Esto explicaría la posibilidad de tener adjuntos agentivos/causativos (ex insidiis/ab omnibus civitates), que se interpretan como Originadores degradados (53). Dado que el argumento que debería estar más alto en la estructura $\left(\mathrm{ARG}_{\text {ORIGINADOR }}\right)$ no se encuentra en la posición esperada (EspecVoice), el argumento más local para establecer la concordancia con T es el que está en EspecPath. T concuerda con este elemento, i.e., copia los rasgos de número y persona, y ese será el nombre que presente caso nominativo.

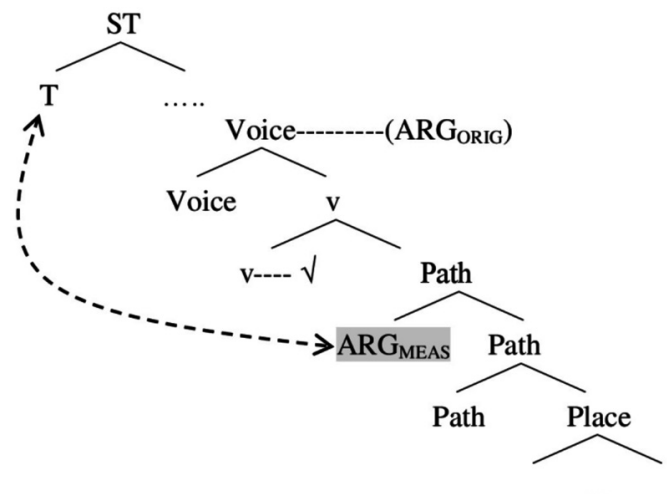

Además del agente, puede degradarse la Figura, como resultado de una configuración defectiva en la que EspecPlace no se proyecta (Acedo-Matellán y Mateu 2013, Acedo-Matellán 2016: 137-139). En ese caso, es el ARG $_{\text {FONDO }}$ el que concuerda con el verbo (54), si no hay ningún argumento nominal (Originador) más alto en la estructura (55). 
(54)

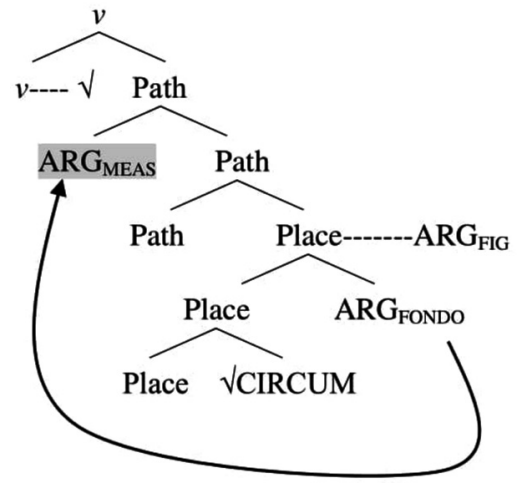

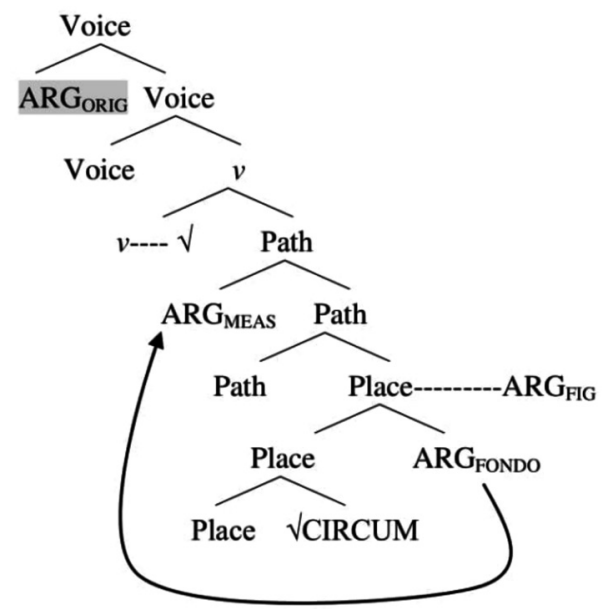

En resumen, la configuración pasiva es una estructura en la que alguna de las proyecciones que introducen argumentos es defectiva. Este hecho altera las relaciones de localidad para la concordancia, en el sentido de que el argumento nominal más local para $\mathrm{T}$ se encuentra más abajo en la estructura. Ese argumento será el que presente morfología de caso nominativo, mientras que si hay un segundo argumento más abajo en la estructura, manifestará caso acusativo, como veremos en $\S 4.3$.

\subsection{La asignación de caso}

Un aspecto central en la Morfología Distribuida (MD) es la postulación de un componente post-sintáctico denominado Estructura Morfológica (EM). En este componente tienen lugar operaciones que no afectan al componente interpretativo, sino que dan cuenta de la falta de isomorfismo entre la estructura que arroja la Sintaxis y la manera en la que esta estructura se materializa finalmente. Algunas líneas de la MD consideran que el caso morfológico es el resultado de operaciones que tienen lugar únicamente en la EM y que son dependientes de la conformación estructural (McFadden 2004). Específicamente en lo relativo al caso, de acuerdo con McFadden, los rasgos se agregan al SD bajo condiciones determinadas por relaciones de localidad con ciertos núcleos y por su posición en la estructura que recibe la EM. Aquí nos referiremos únicamente al caso nominativo y acusativo, para los que McFadden propone los siguientes rasgos:

Nominativo: [+caso]

Acusativo: [+caso, + inferior $]$ 
El nominativo es el caso "por defecto», en el sentido de Marantz (1991) y McFadden (2004); mientras que el rasgo [+inferior] es asignado por un mecanismo de caso dependiente, i.e., es el que se le asigna a un argumento en la estructura, una vez que otro argumento presenta caso nominativo por estar en relación de concordancia.

En todos los ejemplos presentados, la distribución de la información de caso es la prototípica: el argumento nominal con el que se establece la concordancia aparece en caso nominativo, mientras que el argumento que está más bajo en la estructura presenta caso acusativo, siguiendo el principio del caso dependiente. Cualquier argumento degradado, i.e., que no pueda ensamblarse en las posiciones de especificador y complemento relevantes, recibe caso bajo condiciones diferentes, ya que queda afuera de las relaciones de concordancia y dependencia. El esquema de (56) presenta una configuración en la que el argumento más local para establecer la concordancia con el nodo T y que, en consecuencia, manifestará caso nominativo es el introducido por Voice. Por su parte, el argumento que aparece ensamblado en el especificador de Path manifestará el caso dependiente, i.e., acusativo.

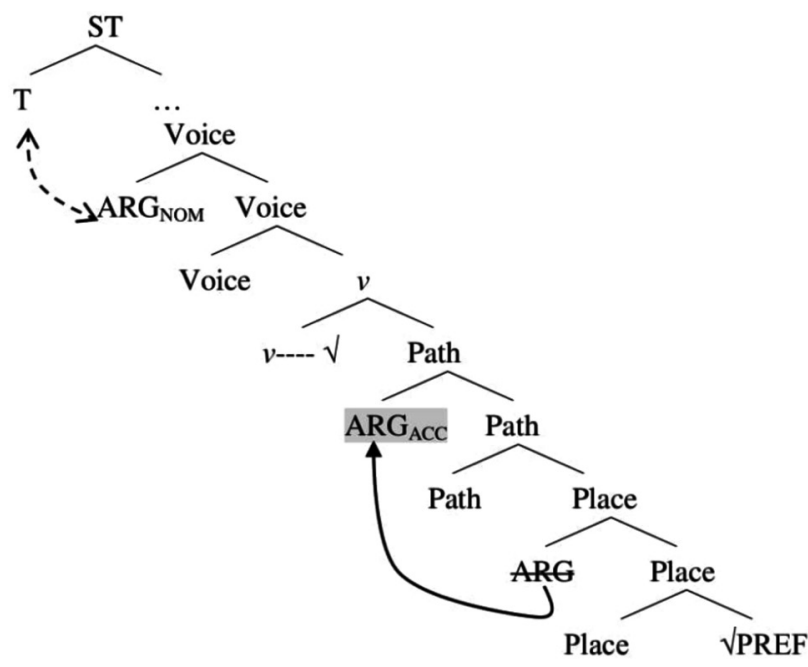

En este sistema, consideramos, pueden explicarse también las construcciones doble acusativo 'reales' (57). El argumento más alto presenta caso nominativo por las razones antes expuestas. El siguiente argumento nominal es dependiente, por lo que manifestará caso acusativo al igual que en (56). Ahora bien, en la estructura hay un argumento más que aparece en una posición estructuralmente relevante: complemento 
de Place. Este elemento no depende de un núcleo aplicativo, ni de otro tipo de $\mathrm{S} p$. Está presente en la estructura y también es dependiente, por lo que se esperaría que recibiera caso acusativo, como efectivamente sucede.

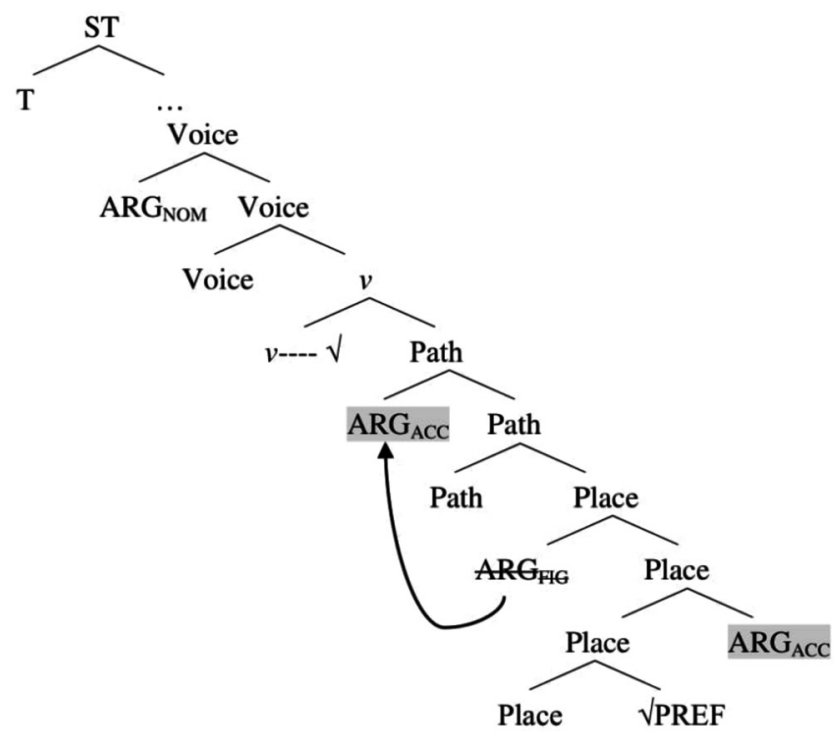

Finalmente, la degradación de cualquiera de los argumentos cambia las condiciones estructurales para el agregado de rasgos de caso en la Estructura Morfológica. Así, si en una configuración como la de (56) o (57) Voice fuera defectivo y ningún elemento nominal pudiera ensamblarse en su especificador, el argumento más local para la concordancia será el primero que se encuentre en la estructura relevante y manifestará caso nominativo, en lugar de acusativo, independientemente de que su presencia pueda estar motivada por un prefijo preposicional que 'marque' a sus argumentos con caso acusativo.

\section{CONSIDERACIONES FINALES}

A lo largo de estas páginas abordamos tanto aspectos descriptivos como discusiones teóricas. A nivel descriptivo, presentamos diferentes ejemplos de verbos prefijados por ante-, circum-, praeter-y trans- en los que se puede reconocer un argumento agregado. En el caso de trans- (fundamentalmente transeo y transduco), reconocimos que la 
presencia de un nombre con caso acusativo está restringida en diferentes sentidos (en línea con las observaciones de Bortolussi 2005, Revuelta Puigdollers 2019).

Mostramos, asimismo, que las construcciones pasivas con estos verbos son productivas. En el caso de los verbos base intransitivos, el objeto no seleccionado termina funcionando como sujeto en la construcción pasiva. Esto no sucede cuando el verbo base es transitivo. Sin embargo, como desarrollamos en la sección 4.2, tal imposibilidad se debe a una cuestión estructural en la jerarquía de los argumentos y no a una dependencia estructural del prefijo preposicional.

Desde el punto de vista teórico, procuramos dar cuenta de las construcciones abordadas, a partir de un modelo neo-construccionista en el que las raíces se ensamblan en diferentes estructuras y no están individuadas ni fonológica ni semánticamente, sino que lo hacen a partir de la computación morfosintáctica (Acquaviva, 2008). Un análisis de este tipo nos permite quitar del eje de la discusión la noción de clases de palabras como definitorias de una estructura (en este fenómeno en particular, la distinción entre prefijos, adverbios y preposiciones) y relacionar la interpretación de los argumentos con posiciones específicas en la estructura.

\section{BIBLIOGRAFÍA}

Acedo-Matellán, V. y J. Mateu (2013): «Satellite-framed Latin vs. verb-framed Romance: A syntactic approach», Probus 25, pp. 1- 39. https://doi.org/10.1515/ probus-2013-0008

Acedo-Matellán, V. (2016): The Morphosyntax of Transitions. A case study in Latin and other languages. Oxford: Oxford University Press. https://doi.org/10.1093/ acprof:oso/9780198733287.001.0001

AcquaVIVA, P. (2008): Roots and lexicality in Distributed Morphology. Ms.: University College Dublin/Universitlat Konstanz. http://ling.auf.net/lingBuzz/000654.

Álvarez Huerta, O. (2009): «Acusativo», en J. M. Baños Baños (coord.) Sintaxis del latín clásico. Madrid: Liceus ediciones, pp. 131-154.

BAKER, M. (1988): Incorporation: a theory of grammatical function changing. Chicago: University of Chicago Press.

Baños Baños, J. M. (2009): «Preposiciones», en J. M. Baños Baños (coord.) Sintaxis del latín clásico. Madrid: Liceus ediciones, pp. 299- 348.

Bibliotheca Classica Latina. (1820): Caius Julius Caesar. Ad codices parisinos recensitus. Julii Celsi comentariis. Vol. II Paris. 16. 
BobaliJK, J. (2008): «Where's $\Phi$ ?: Agreement as a Post-syntactic Operation», en M. Van Koppen, P. Hendriks, F. Landsbergen, M. Poss y J. van der Wal (eds.). Special Issue of Leiden Papers in Linguistics 3 (2), pp. 1-23.

Bortolussi, B. (2005): «Le double accusatif avec les verbes prefixes en circum- et trans-», en C. Moussy (ed.) La composition et la preverbation en latin. Paris: Presses de l'Université Paris-Sorbonne, pp. 277-292.

Chомsкy, N. (1957): Syntactic Structures. The Hague/Paris: Mounton.

Coluins, C. (2005): «A smuggling approach to the passive in English», Syntax 8, pp. 81-120. https://doi.org/10.1111/j.1467-9612.2005.00076.x

CrocCo GalĖAS, G. y C. IACOBINI (1993): Lo sviluppo del tipo verbale parasintetico in latino: i prefissi AD-, IN-, EX-. Quaderni Patavini di inguistica 12, pp. 31-68.

De Valbuena, M. (1789): Los comentarios de Cayo Julio Cesar. Madrid: Imprenta real. Ernout, A. y F. Thomas (1953): Syntaxe Latine. Paris: Klincksieck.

GarCíA-HernándeZ, B. (1996): «Modificación prefijal y régimen sintáctico. El testimonio de Arusiano Mesio», en R. Risselada, J. R. de Jong y A. M. Bolkestein (eds.), On Latin. Linguistic and Literary Studies in Honour of Harm Pinkster, Ámsterdam, pp. 25-43.

Halle, M. y A. Marantz (1993): «Distributed Morphology and the pieces of inflection», en K. Hale y S. Keyser (eds.) The View from Building 20. Cambridge, Mass.: MIT Press, pp. 111-176.

KÜHNER, R. y C. STEGMANN (1914): Ausführliche Grammatik der lateinischen Sprache. Hannover: Hahn.

MarantZ, A. (1991): «Case and licensing», en G. Westphal, B. Ao y H. R. Chae (eds.), Proceedings of ESCOL 91, Cornell University, Ithaca, NY: Cornell Linguistics Club, pp. 234-253.

MARE, M. (2018): «Issues on word formation. The case of Latin circum», The Linguistic Review, 35/1, pp. 121-160. https://doi.org/10.1515/tlr-2017-0019

Mateu, J. (2002): Argument Structure. Relational Construal at the Syntax-Semantics Interface. Bellaterra: Universitat Autònoma de Barcelona dissertation. https:// ddd.uab.cat/pub/tesis/2002/tdx-1021103-173806/tdx.html (12 September 2010).

MCFADDEN, T. (2004): The position of morphological case in the derivation: a study on the syntax-morphology interface. Doctoral Dissertation, University of Pennsylvania, Philadelphia.

McLachlan, K. (2012): Verborum ordo - ordo verborum: the placement of the dependent genitive in Classical Latin. Tesis de doctorado. Universidad de Oxford. 
OnIGA, R. (2005): Latin. A linguistic introduction. Oxford: Oxford University Press. Pinkster, H. (2015): Oxford Latin Syntax. Volume 1: The simple clause. Oxford: University Press.

Revuelta-Puigdollers, A. (2016): «A cognitive-functional study of the prefix circum: the non-prototypical cases», en Paolo Poccetti (ed.). LATINITATIS RATIONES. Descriptive and Historical Accounts for the Latin Language. Berlin: De Gruyter, pp. 127-146. https://doi.org/10.1515/9783110431896-011

Revuelta-Puigdollers, A. (2019): «El preverbio trans- en latín: descripción práctica y aproximaciones teóricas», ponencia presentada en el XLVIII Simposio de la Sociedad Española de Lingüística. Madrid, 30/01/2019.

Svenonius, P. (2008): «Projections of P», en A. Asbury, J. Dotlačil, B. Gehrke y R. Nouwen (eds.) Syntax and Semantics of Spatial P. Amsterdam: Benjamins, pp. 63-84. https://doi.org/10.1075/la.120.04sve 